\title{
(RE)PENSANDO O DIREITO DIANTE DA SOCIEDADE DE RISCO: CONSIDERAÇÕES SOBRE A EMERGÊNCIA DA MUDANÇA DO PARADIGMA AMBIENTAL NA AMÉRICA LATINA $^{1}$
}

\author{
Angelita Woltmann ${ }^{2}$ \\ Raquel Buzatti Souto ${ }^{3}$ \\ Maiara Cristina Schneider Campos ${ }^{4}$
}

\begin{abstract}
RESUMO
O objetivo deste trabalho é examinar o Direito em face da idéia de modernidade que, embora traduza o bem-estar mundial, encontra-se sob questionamento, eis que, ao mesmo tempo em que encanta, traz medos e incertezas, tornando a sociedade e a própria comunidade científica cautelosa para evitar desastres de proporções inimagináveis. A crise ambiental assume cada vez mais novas características em face dos riscos produzidos na sociedade industrial e biotecnológica, e o humano, através de empresas nacionais e transnacionais investe em pesquisas cujos resultados podem comprometer seriamente a natureza e a saúde de todos os seres vivos. Em contrapartida, a legislação aplicada a tais assuntos na América Latina encontra-se estagnada e envolta em interesses políticos e econômicos, típicos da sociedade de risco que assume a feição da crise ambiental na sociedade. É imprescindível que o Direito latino-americano seja (re)pensado, portanto, sob o viés da crise global. Assim, justifica-se o presente estudo.
\end{abstract}

Palavras - chave: Direito. Risco. Ambiente. América Latina

\footnotetext{
${ }^{1}$ Artigo desenvolvido pelas pesquisadoras nos Grupos de Pesquisa GPJUR, do Curso de Direito e Núcleo de Estudo e Pesquisa em Práticas Sociais, interdisciplinar, ambos da Universidade de Cruz Alta (UNICRUZ) que pesquisam o tema desde que foram instigadas pelas aulas da disciplina "A Constituição: construtora da disciplina de Direito Ambiental”, ministrada pelo Prof. Dr. Luiz Ernani Bonesso de Araújo , durante o curso de Pós-graduação lato sensu em Direito Constitucional aplicado, do Centro Universitário Franciscano.

${ }^{2}$ Doutoranda em Ciências Jurídicas pela Universidade de Buenos Aires. Mestre em Integração LatinoAmericana pelo Mestrado em Integração Latino-Americana (MILA) da Universidade Federal de Santa Maria (UFSM) na linha de pesquisa Direito da Integração. Especialista em Direito Constitucional aplicado pelo Centro Universitário Franciscano (UNIFRA). Especialista em Bioética pela Universidade Federal de Lavras (UFLA). Professora e coordenadora do Núcleo de Trabalho de Conclusão do Curso de Direito da Universidade de Cruz Alta (UNICRUZ). Coordenadora da $5^{\text {a }}$ edição da Pós-Graduação em Direito Civil e Processual Civil da Universidade de Cruz Alta. Advogada. E-mail: awoltmann@gmail.com .

${ }^{3}$ Mestre em Desenvolvimento pela Universidade Regional do Noroeste do Estado do Rio Grande do Sul (UNIJUÍ), na linha de pesquisa Direito, Cidadania e Desenvolvimento. Especialista em Direito Constitucional Aplicado: uma abordagem material e processual pela UNIFRA. Coordenadora e Professora do Curso de Direito da Universidade de Cruz Alta. Coordenadora da $5^{\text {a }}$ edição da PósGraduação em Direito Civil e Processual Civil da Universidade de Cruz Alta. Advogada. E-mail: rsouto@unicruz.edu.br.

Acadêmica do $10^{\circ}$ semestre do curso de Direito da Universidade de Cruz Alta. Estagiária na Procuradoria da República no Rio Grande do Sul- Ministério Público Federal, sede Cruz Alta. E-mail: maiaracscampos@gmail.com.
} 

$\mathrm{Na}$ atualidade, graves problemas estão a afligir a humanidade, com especial destaque, os decorrentes da expansão ilimitada da biotecnologia, geradora de desequilíbrios ambientais. As mudanças climáticas, a diminuição da camada de ozônio, a chuva ácida, a perda da biodiversidade, os problemas do lixo e da água, o crescimento populacional associado à pobreza e degradação dos recursos ambientais, e ainda, questões mais específicas que ocupam o cenário mundial recente, também atingem à América Latina. A globalização exerce grande contribuição na emergência da problemática ambiental, sendo um processo complexo e contraditório, inerente à expansão do capitalismo, intrinsecamente ligada ao advento da modernidade.

Vive-se em um universo no qual se processam rápidas e profundas transformações biotecnológicas, sociais e culturais. Aqueles valores e princípios que serviam como referências seguras para a vida do homem em sociedade não mais fornecem respostas satisfatórias diante dos usos possíveis das novidades biotecnológicas 5 .

De acordo com os ensinamentos de Telles (2003, p. 176-177), o termo biotecnologia foi cunhado no ano de 1919, por Karl Ereky, engenheiro húngaro. Em um período de escassez entre-guerras, esse engenheiro defendeu um método de produção de alimentos aplicando os fundamentos da produção industrial. A esse método ele denominou biotecnologia. Todavia, o termo só posteriormente foi aplicado para denominar a ação da fabricação de alimentos utilizando-se de organismos vivos. Apesar de o termo biotecnologia ter sido introduzido no mundo em 1919, há séculos a humanidade já fazia cruzamentos entre plantas e animais (experiências genéticas rudimentares e empíricas) objetivando seu melhoramento para utilização e consumo. Entretanto, o crescimento acelerado do campo da biotecnologia ocorreu somente a partir da década de 70, com o desenvolvimento da engenharia genética ou tecnologia do ácido desoxirribonucléico (DNA) recombinante ${ }^{6}$.

\footnotetext{
5 Exemplos de substâncias ou produtos que têm sido produzidos por meio da biotecnologia moderna ou engenharia genética incluem interferon humano (substância natural sintetizada no organismo humano para defesa contra vírus), insulina humana, hormônios de crescimento humano, plantas resistentes a vírus, plantas tolerantes a insetos e plantas resistentes a herbicidas. Outro uso importante da biotecnologia implica na produção de bactérias, utilizadas para biodegradação de vazamentos de óleos ou lixos tóxicos. Fonte: 〈http://www.abrabi.org.br/biotecnologia.htm> Acesso em: 15 abr. 2010.

$6 \quad$ Esta tecnologia implica na modificação direta do genoma do organismo alvo pela introdução intencional de fragmentos de DNA exógenos (genes exógenos) que possuem uma função conhecida. Fonte: <http://www.abrabi.org.br/biotecnologia.htm> Acesso em: 15 abr 2010.
} 
Da metade do século XX em diante, as regras científicas começaram a ser questionadas em diferentes campos. O fim da certeza acelerou-se na mesma ligeireza da proposição de soluções definitivas. O uso do DDT e dos antibióticos foram casos exemplares. Além disso, conceitos como causa de doenças, herdados da bacteriologia tornaram-se insuficientes para explicar as doenças não transmissíveis. Com isso, ganharam força as proposições que enfatizavam o contexto, onde diferentes aspectos (ou fatores de risco) estariam contribuindo para o fenômeno em estudo. (LIEBER \& ROMANO LIEBER, 2001).

Imerso em um processo de aceleração, o homem não se questiona do sentido da busca desenfreada por poder e não reflete sobre seu comportamento frente à biotecnologia. Esse é o centro da crise ético-ambiental vivida na atualidade. E, para que, dentro da sociedade atual, repleta de riscos ${ }^{7}$ e incertezas ${ }^{8}$, o homem rompa com esse pensamento egoísta e ao mesmo tempo, que o latino-americano se submeta ao sistema de dominação que há no continente, deve educar a si mesmo ${ }^{9}$ e ter em mente que é, ao mesmo tempo, indivíduo, parte da sociedade e parte da espécie (MORIN, 2000).

$\mathrm{O}$ modelo de racionalidade utilizado até então integra uma visão de mundo mecanicista, herdada de Descartes. Para esse pensador, tudo não passava de uma máquina, de uma grande máquina. Foi este fascínio pela máquina, em especial, o relógio, que o levou a criar sua principal metáfora: "Vejo o corpo como nada mais que uma máquina" (DESCARTES, 1973). A partir dessa visão, os cientistas começaram a enxergar a natureza, realmente como uma grande máquina, um imenso relógio, e para compreendê-la, bastaria desmontá-la, reduzi-la a um monte de peças fáceis de entender, analisá-las uma a uma, e, a partir daí, se passaria a entender o todo ${ }^{10}$.

\footnotetext{
${ }^{7}$ Expressão habitualmente utilizada por Fridjof Capra para caracterizar a sociedade atual.

${ }^{8}$ Expressão habitualmente usada por Edgar Morin para caracterizar a sociedade atual.

${ }^{9}$ Importa referir que Morin ensina que há que se fazer uma total reorganização da educação, impondo-se o uso da interdisciplinariedade no ensino. O pensador aduz que os sete saberes necessários para o ensino do futuro são: I. reconhecer as cegueiras do conhecimento, seus erros e ilusoes; II. assumir os princípios de um conhecimento pertinente; III. condiçao humana; IV. identidade planetária; V. enfrentar as incertezas; VI. compreender e VII. a ética do gênero humano.

${ }^{10}$ Importa ressaltar que a nova visão, a qual se pretende abordar nesse trabalho, e é ferrenhamente estudada por Fritjof Capra, preconiza que o todo não é somente a soma das partes, e sim, muito mais do que isso, uma vez que tudo está interligado. (2000, p. 46)
} 
Como uma perspectiva frente a esse paradigma cartesiano apresenta-se a visão sistêmica de Fritjof Capra ${ }^{11}$. De acordo com a teoria desse estudioso, quanto mais se pesquisa sobre os principais problemas de nossa época, mais somos levados a perceber que eles não podem ser entendidos isoladamente. São problemas sistêmicos, o que significa que estão interligados e são interdependentes. Inclusive, são problemas que necessitam ser vistos como diferentes facetas de uma única crise.

Surge então a concepção de risco como sendo a imprevisibilidade dos efeitos de uma decisão assumida, onde uma escolha entre outras alternativas sempre terá o risco como uma constante inafastável. Isto porque, desde o momento em que a sociedade percebeu não existir a segurança que buscava, por não ser possível alcançar a certeza científica sobre determinados fatos, passou-se a acreditar que a alternativa para o risco, era um risco de outro gênero, e não a segurança (DE GIORGI, 1998).

Tal construção teórica, preconizada por Ulrich Beck na obra Sociedade de Risco, de $1986^{12}$, aproxima-se muito da realidade latino-americana. Beck (1997, p. 15) ainda enuncia que como uma teoria social e como um diagnóstico de cultura, o significado da expressão sociedade de risco designa um estágio da modernidade em que começam a tomar corpo as ameaças produzidas até então no caminho da sociedade industrial.

A evolução científica está a exigir reflexão, clamando por um repensar, não só das outras ciências, como do Direito, eis que, na atual sociedade, os saberes são especializados e compartimentados em diversas disciplinas, sem uma maior interação, levando à fragmentação de diversos saberes. Com efeito, a especialização gera um conhecimento privativo, desconsiderando o todo, tornando o homem incapaz de compreender a complexidade contemporânea.

11 Salienta-se que a Teoria Sistêmica surgiu com Von Bertalanffy, a partir de uma reflexão sobre biologia, espalhou-se, a partir dos anos 50 de maneira profusa nas mais diferentes direções. (MORIN, 2003, p.28). Além de Fritjof Capra, - ao qual está se dando maior ênfase neste artigo -, inúmeros outros estudiosos importantíssimos no mundo todo defendem esse pensamento, a exemplo de Edgar Morin, Nicklas Luhmann, Ilya Prigogine, Humberto Maturana, Francisco Varela, Lynn Margulis, Benoit Mandelbrot, Stuart Kauffman, Leonel Severo Rocha, entre outros, para citar apenas alguns nomes.

12 Nesta obra, Beck propõe a distinção entre uma primeira e uma segunda modernidade. A primeira caracteriza-se por ser estatal e nacional, de estruturas coletivas, pleno emprego, rápida industrialização, e exploração da natureza não visível. Tal modelo tem profundas raízes na sociedade européia, através das várias revoluções políticas e industriais, a partir do século XVIII. Em contrapartida, hoje, já na segunda modernidade, que Beck chama de modernização da modernização ou também modernidade reflexiva, as assunções fundamentais, as insufiências e as antinomias da primeira modernidade são postas em questão. Informação retirada de ASSMANN, Selvino. A sociedade global do risco. Uma discussão entre Ulrich Beck e Danilo Zolo. Disponível em: <http:www.cfh.ufsc.br/ wfil/ulrich.htm> Acesso em: 23 jul. 2004. 


\section{A CRISE DE CONSCIÊNCIA ÉTICO-AMBIENTAL NO DIREITO LATINO AMERICANO COMO IMPULSIONADORA DE UM "REPENSAR" PARADIGMÁTICO}

Assim, o homem passa a dar-se conta de que precisa agir e, nesse momento, passa a pensar com maior responsabilidade os problemas ambientais, base de todos os demais sistemas, chegando à conclusão de que estes necessitam ser solucionados, ou, ao menos, abrandados. No entanto, sente-se impotente frente à imensidão do caos ambiental que já se instalou no planeta. Impotente porque não consegue se desprender da ganância de cada vez adquirir mais, sem, muitas vezes, a consciência que os recursos naturais, os quais necessita para a sobrevivência da própria espécie, são limitados e podem se esgotar. Ao revés, felizmente, tem aumentado a percepção de que o humano, ou altera seus valores, ou caminhará para a autodestruição.

De acordo com a visão sistêmica, defendida por Capra (2000, p. 24), para a compreensão desses problemas globais é preciso que o homem insira-se no sistema vivo. Ou seja, para que o humano encontre sua nova percepção, sua nova consciência, necessita abandonar a visão cartesiana da mente como um objeto, aproveitar-se das experiências vividas, através de sua percepção, emoção e comportamento e trocar o objetivismo pelo subjetivismo na forma de encarar os problemas (CAPRA, 2002). Somente desse modo haverá efetivamente a percepção do processo da vida e a efetivação do pensamento sistêmico.

Dessa maneira, o homem poderá agir conscientemente na defesa de seu ambiente, sabendo claramente que é integrante do mesmo. Outrossim, para isso é imprescindível uma alteração $^{13}$ em seus valores, em suas percepções, em seus pensamentos, em seus conceitos. Bauman (2001, p. 15) traduz exatamente esse entendimento quando aduz que a "modernidade líquida" impõe que repensemos os velhos conceitos, eis que "Como zumbis, esses conceitos são hoje mortos-vivos. A questão prática consiste em saber se sua ressurreição, ainda que em nova forma ou

13 Quando se fala em alteração, não significa que seja preciso deixar para traz tudo o que já foi construído, apenas que o homem deve mudar alguns de seus valores, pensamentos, percepções, conceitos. Aquilo que for bom para sua relação com a natureza não precisa ser modificado e sim, aprimorado, talvez, reiventado. Como bem refere Capra (2000, p. 26), eventualmente não é preciso se desfazer de tudo, mas, antes disso, é preciso estar disposto a questionar tudo. 
encarnação, é possível; ou - se não for - como fazer com que eles tenham um enterro decente e eficaz."

Referindo-se quanto a fundamentalidade da ecologia profunda, Capra (2000, p. 27) considera necessária uma mudança na visão de mundo, onde todos os seres vivos serão membros de uma comunidade ecológica que predomina a interdependência de todas as vidas, humana e não humana. De outro lado, mas de modo igualmente importante, principalmente na América Latina, Castells (1999, p. 142) refere que é necessária uma transformação nos meios de produção e de consumo, bem como de uma organização social e da vida pessoal do ser humano.

Para a obtenção dos efeitos da visão sistêmica impõe-se uma evolução do paradigma baseado em valores centralizados no homem (antropocêntrico) para os centralizados na Terra como um todo (ecológica). Na medida em que o homem perceber-se disto, sentir-se-á parte do todo e o pensamento sistêmico acontecerá.

Nesse passo, a necessidade de passar por essa mudança passa também pelo cenário jurídico latino-americano, que, como sistema comprometido, não pode projetarse qual um instrumento de desenvolvimento e regulamentação da consciência ambiental numa sociedade a qual não conhece. Todos esses pressupostos, que contextualizam o ser humano e o fazem entrar em interação com a estrutura da sociedade em que vivem, devem ser norteadores das percepções do Direito ambiental, de seus desafios e de suas perspectivas.

O Direito, dotado da tarefa de estabelecer restrições, sem, no entanto, engessar o desenvolvimento de novas pesquisas que poderão ser de grande utilidade para a sociedade faz-se imprescindível para preservação da própria vida humana inserida em seu ambiente. Deixar que disciplinas como a Bioética, por exemplo, sozinhas, determinem os caminhos e a extensão dos riscos da sociedade atual, significaria gerar uma insegurança no corpo social, visto que o que é ético para uns pode não ser para os demais. Haveria também o problema de como cobrar, restringir ou penalizar com base em algo tão abstrato. Cair-se-ia em um verdadeiro abismo diante de tamanha insegurança jurídica gerada. Todavia, o Direito não pode se confrontar com o progresso da ciência. É uma constatação, o fato de a ciência jurídica, assim como está articulada, 
não possui condições de dar conta desses desafios ${ }^{14}$, porque as normas do Direito tradicional e dos institutos que o compõem não conseguem dirimir os conflitos suscitados pelas novidades da ciência (OLIVEIRA JÚNIOR, 2000). A transformação da sociedade está frente aos nossos olhos, pedindo respostas aos chamados novos direitos, clamando por uma nova ordem jurídica capaz de atender adequadamente as demandas da sociedade de risco.

Os juristas do tempo atual estão diante da necessidade de se preparar para a solução de novos problemas trazidos pelas mudanças tecnológicas e sócio-culturais que estão a ocorrer numa velocidade imensurável. No contexto atual, o Estado-Nação vem sendo pressionado a regular novas condutas, nem sequer pensadas até então, o que por vezes acaba gerando grandes equívocos e precipitações catastróficas. Inclusive, nesse sentido, importa salientar que organizações ambientalistas de grande vulto, como o Greenpeace, são totalmente antinacionalistas. David McTaggart, líder histórico da ONG entende que a maior ameaça que precisa ser combatida é o nacionalismo, eis que se está diante de questões que não podem mais ser abordadas simplesmente no âmbito nacional. (CASTELLS, 1999).

Trata-se da necessidade de buscar um entendimento que integre os diferentes modos de pensar, deixando de lado mecanismos reducionistas, simplificadores e disjuntivos, para abranger os mais variados aspectos que cada problemática envolve. É um processo científico também complexo. Se o risco é inafastável na sociedade, cabe ao Direito delimitar o grau de tolerabilidade destes riscos. Ponderar, dentre os riscos que se apresentam, quais os aceitáveis, ou seja, quais os riscos que pode suportar. Nesse sentido, o Direito não irá eliminar os riscos, nem trazer segurança, mas sim, vislumbrando os mais variados aspectos possíveis, a partir da visão de todos os ramos do saber que tem envolvimento com a problemática, irá estabelecer as normas para o gerenciamento destes riscos, definindo quais as atividades que apesar de portarem riscos ambientais, podem ser admitidas pela sociedade ou não.

Importante salientar nesse processo de bioeticização do Direito que, a partir de 1972, uma nova maneira de compreender o meio ambiente se estabeleceu na América Latina, através da Conferência das Nações Unidas sobre o Meio Ambiente Humano realizada em Estocolmo, Suécia. As regras de Direito Ambiental, que até então eram

$14 \quad$ Necessidade do surgimento dos chamados novos direitos. 
dispersas e voltadas apenas para o âmbito interno, começaram a ser sistematizadas também em âmbito internacional. Por essa razão, houve um aumento significativo do número de instrumentos de proteção ambiental que deixaram de lado a preocupação exclusiva com as regras internas e regionais. Com isso, a preservação do meio ambiente passou a ser uma bandeira mundialmente defendida.

Outro marco da história do Direito Ambiental Internacional foi a realização da Conferência das Nações Unidas sobre Meio Ambiente e Desenvolvimento (ECO-92). Esse encontro, realizado no Rio de Janeiro, contou com a participação de 178 Governos e a presença de mais de 100 Chefes de Estado ou Governo. Além de buscar uma consciência ambiental, foi marcante pela busca de proteção jurídica ao meio ambiente. Da ECO-92 ressaltam-se os seguintes resultados: a) adoção de uma Declaração de princípios sobre ambiente de desenvolvimento; b) adoção de duas Convenções multilaterais mundiais, uma sobre diversidade biológica e outra sobre alterações climáticas e; c) a adoção de um plano de ação na comunidade internacional referente à implementação dos objetivos fixados na Declaração do Rio (desenvolvimento sustentável), este documento ficou conhecido por Agenda 21. No ano de 2012, buscando o repensar da crise ambiental em que o globo está inserido, foi realizada a Conferência das Nações Unidas sobre Desenvolvimento Sustentável (CNUDS), popularmente conhecida como "Rio+20". No entanto, apesar dos debates e grandiosidade do evento, houve mais críticas e promessas do que concretização de normatização internacional de fato ${ }^{15}$.

A busca pela efetivação de um Direito Ambiental Internacional para a América Latina passa pelo enfrentamento das questões comerciais. A evolução desses novos ramos do Direito traz consigo implicações diretas e decisivas para as relações internacionais, especialmente no que se refere à prática de medidas de proteção ambiental e do próprio ser humano em confronto com o livre comércio. $\mathrm{O}$ aumento no número de tratados e convenções internacionais demonstra que a preocupação em regulamentar tanto o comércio internacional como os mecanismos de proteção ambiental são um objetivo almejado mundialmente. Porém, esses mesmos textos

\footnotetext{
${ }^{15}$ Em contrapartida, como ponto positivo, os eventos que ocorreram paralelamente - Cúpula dos Povos e a Cúpula Empresarial - foram vistos como positivos em virtude do debate e troca de experiências dos voluntários nas mais diversas questões ambientais, notadamente a emissão de gases CO2.
} 
normativos podem trazer consigo instrumentos que geram dúvida e incerteza sobre como devem ser aplicados.

\section{CONSIDERAÇÕES FINAIS}

Tendo em vista o contexto exposto, do mal-estar do homem e do próprio Direito na sociedade de risco, a reflexão que pode ser feita é de que, antes de nada, o próprio ser humano reconheça que precisa encontrar uma nova percepção, uma nova consciência, novos valores, enfim, que precisa operar uma verdadeira mudança de paradigmas, livre de uma visão do mundo obsoleto a qual está acostumado. Para que tal mudança de percepção se efetive, é necessário abandonar aquela visão cartesiana, que entende a mente como uma coisa, aproveitando-se das experiências vividas, através da percepção, emoção e comportamento, encontrando no subjetivismo uma nova forma de encarar os problemas globais. Ademais, é importante admitir que todos os sistemas, assim como os problemas e as crises estão interligados. Ao focar-se a biotecnologia como um sistema, pode-se visualizar a importância de uma visão integrada e sistêmica onde nenhum sistema é independente, nem pode sobrepor-se ao outro. O Direito ambiental latino-americano, mesmo impotente frente ao progresso da ciência e da biotecnologia, por sua vez, não pode andar para o futuro sem o apoio de outras ciências, pois só assim se poderá esperar um maior empreendimento na busca de entendimentos para os inúmeros questionamentos gerados pelo paradoxo entre a vida humana e o desenvolvimento da ciência. Muito embora o Direito Ambiental Internacional esteja se cercando de instrumentos jurídicos e políticos para garantir um desenvolvimento sustentável, tais instrumentos em sua grande maioria são desprovidos de medidas sancionadoras àqueles que as descumprem. Os homens atuantes na sociedade contemporânea correm incessantemente na busca do material imediato. Como diz Morin (1995, p. 155), "a velocidade é a doença da civilização, que traz a urgência de diminuir a marcha.”. Embora se saiba que o conhecimento científico não cessará, até porque seria ruim para a humanidade, a falta de freios no processo biotecnológico aumenta o mal estar social, visto que ainda paira a incerteza cientifica quanto a suas futuras conseqüências. 


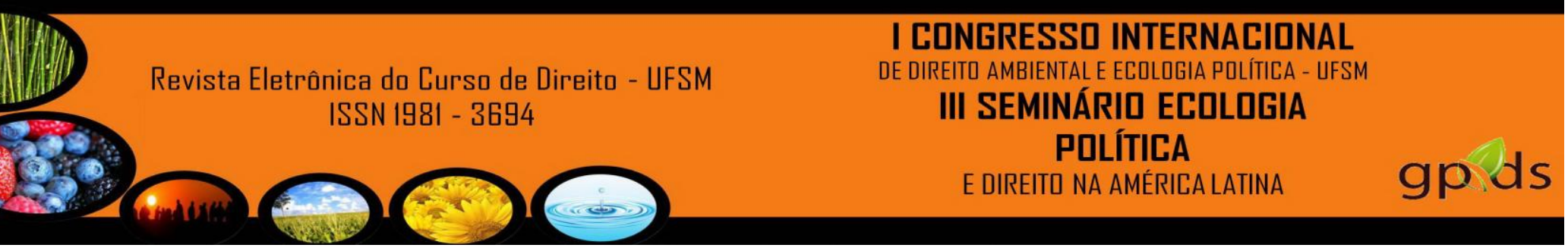

REFERÊNCIAS

ASSMANN, Selvino. A sociedade global do risco. Uma discussão entre Ulrich Beck e Danilo Zolo. Disponível em: <http:www.cfh.ufsc.br/ wfil/ulrich.htm> Acesso em: 23 jul. 2004.

BAUMAN, Zygmunt. Modernidade Líquida. Traduzido por Plínio Dentzien. Rio de Janeiro: Jorge Zahar, 2001.

BECK, Ulrich. A reinvenção da política: rumo a uma nova teoria da modernização reflexiva. In: Modernização Reflexiva: Política, Tradição e Estética na Ordem Social Moderna. Tradução de Magda Lopes. São Paulo: Editora da Universidade Estadual Paulista, 1997.

BELLINO, Francesco. Fundamentos da Bioética: aspectos antropológicos, ontológicos e morais. Traduzido por Nelson Souza Canabarro. Bauru, SP: EDUSC, 1997.

BRASIL. Constituição. Brasília: Senado Federal, 1988.

CAPRA, Fritjof. As conexões ocultas. Ciência para uma vida sustentável. . Traduzido por Marcelo Brandão Cipolla. 11. ed. São Paulo: Cultrix, 2002.

A Teia da vida : uma nova compreensão científica dos sistemas vivos. Traduzido por Newton Roberval Eichemberg. 9. ed. São Paulo: Cultrix, 2000.

CASTELLS, Manuel. O "verdejar" do ser: o movimento ambientalista. In: O poder de identidade. São Paulo: Paz e Terra, 1999.

DE GIORGI, Raffaele. Direito, Democracia e Risco: vínculos com o futuro. Porto Alegre: Sérgio Antonio Fabris, 1998. 


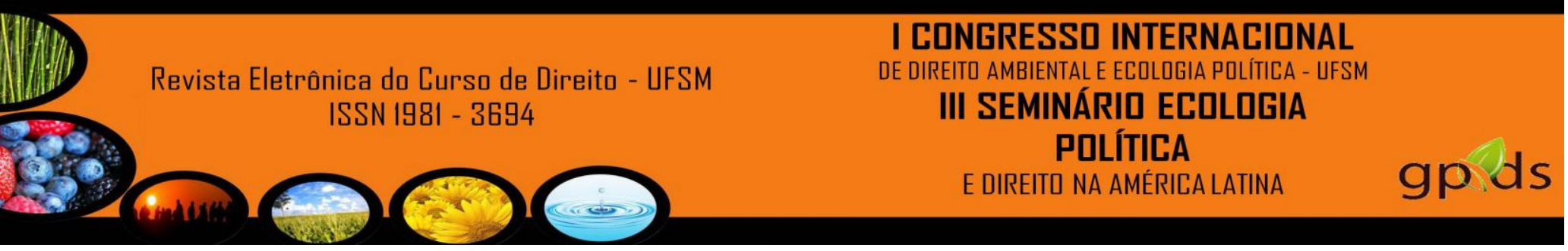

DESCARTES, René. Discurso do Método. Trad. J. Guinsburg e Bento Prado Jr. São

Paulo: Abril Cultural, 1973.

. Discurso do método; As paixões da alma. 4. ed. 2 V. São

Paulo: Nova Cultural, 1987.

GIDDENS, Anthony. A vida em uma socieade pós-tradicional. In: Modernização Reflexiva: Política, Tradição e Estética na Ordem Social Moderna. Tradução de Magda Lopes. São Paulo: Editora da Universidade Estadual Paulista, 1997.

LIEBER, Renato Rocha; ROMANO LIEBER, Nicolina Silvana. O conceito de risco: Janus reiventado. In: MINAYO, Maria Cecília de Souza; MIRANDA, Ary Carvalho de. Saúde e ambiente sustentável: estreitando nós. Rio de Janeiro: FIOCRUZ, 2002.

LUHMAnN, Niklas. A Nova Teoria dos Sistemas. Trad. Eva Machado Barbosa Samios. Porto Alegre: Universidade/UFRGS, Goethe - Institut/ICBA, 1997.

Sociologia del Riesgo. Guadalajara: Universidad Iberoamericana/ Universidad de Guadalajara, 1992.

MORIN, Edgar. Os sete saberes necessários à educação do futuro. São Paulo: Cortez, 2000.

Introdução ao pensamento complexo. Traduzido por Dulce Matos. 4. ed. Lisboa: Piaget, 2003.

; MOIGNE, Jean-Louis Le. A inteligência da complexidade. 2. ed.

São Paulo: Peirópolis, 2000.

; KERN, Anne Brigitte. Terra-Pátria. Traduzido por Paulo Azevedo Neves da Silva. Porto Alegre: Sulina, 1995. 


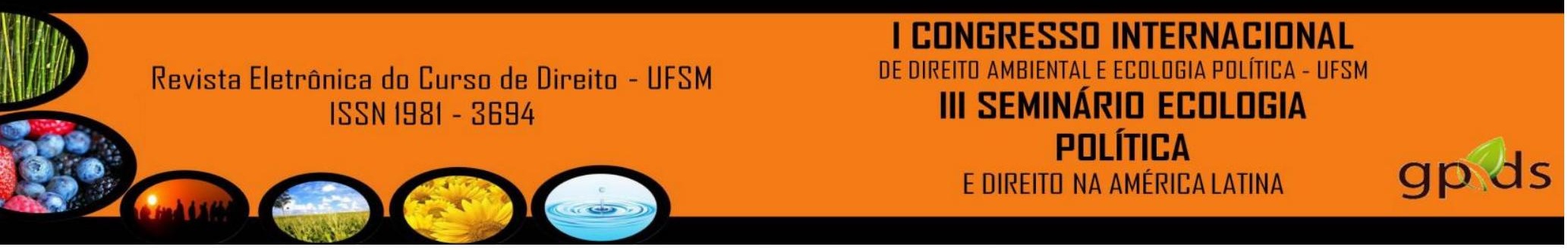

OLIVEIRA JUNIOR, José Alcebíades de. Teoria Jurídica e Novos Direitos. Rio de Janeiro: Lúmen Júris, 2000.

OST, François. A natureza à margem da lei: a ecologia à prova do direito. Traduzido por Joana Chaves. Lisboa: Piaget, 1995.

SOARES, Guido Fernando Silva. Direito Internacional do Meio Ambiente. São Paulo: Atlas, 2001.

VALlE, Silvio; TELLES, José Luiz. Bioética e biorrisco: abordagem transdisciplinar. Rio de Janeiro: Interciência, 2003. 